\title{
Fetal Neutrophils and Eosinophils Express Normal Levels of L-Selectin ${ }^{1}$
}

\author{
JEFFREY B. SMITH AND KHALIL M. A. TABSH \\ Divisions of Neonatology and Maternal-Fetal Medicine, UCLA School of Medicine. Center for the Health \\ Sciences, Los Angeles, California 90024
}

\begin{abstract}
L-selectin is a leukocyte adhesion molecule important in the initial stages of the interaction of neutrophils with endothelium during neutrophil emigration from the bloodstream. Neutrophils and eosinophils from newborn infants express significantly less $\mathrm{L}$-selectin than do neutrophils and eosinophils from adults. It is not known whether $\mathrm{L}$-selectin expression on fetal granulocytes is similarly decreased. We studied fetal blood specimens obtained for a variety of clinical indications by percutaneous umbilical cord sampling at 23 to 34 wk of gestation and measured L-selectin expression by flow cytometry. Eosinophils constituted a large proportion of the granulocytes in these fetal specimens $(42 \pm 26 \%, n=8)$, with eosinophil counts ranging from 180 to $690 / \mathrm{mm}^{3}$ (mean \pm SD: $350 \pm$ 220). There was no difference in L-selectin expression of unstimulated fetal and adult neutrophils (mean \pm SD specific fluorescence: $53.0 \pm 6.8$ versus $56.6 \pm 4.3, n=6$ ), and no difference between unstimulated fetal and adult eosinophils $(16.0 \pm 6.5$ versus $18.7 \pm 3.2, n=6)$. Thus, neutrophils and eosinophils from fetuses as early as $23 \mathrm{wk}$ express L-selectin at adult levels. Furthermore, fetal neutrophils and eosinophils shed the receptor normally in response to stimulation in vitro. We conclude that the reduction of $\mathrm{L}$-selectin expression on neonatal neutrophils and eosinophils is not due to an inherent developmental limitation, but instead must be caused by changes occurring in the neonatal period. Elucidation of the etiology of these changes may aid in the development of therapeutic measures to correct the L-selectin-related defects of neonatal neutrophil adherence. (Pediatr Res 34: 253-257, 1993)
\end{abstract}

\section{Abbreviations}

FMLP, $N$-formyl-methionyl-leucyl-phenylalanine HBSS, Hanks' balanced salt solution PE, phycoerythrin

L-selectin, a member of the selectin family of cell adhesion molecules, plays a critical role in the initial rolling interaction of neutrophils with activated endothelium (1-4). The rolling interaction greatly reduces the speed of neutrophils in small venules and is a prerequisite for the $\beta_{2}$-integrin-mediated interactions that produce firm adhesion of neutrophils and subsequently their

Received January 19, 1993; accepted April 8, 1993

Correspondence and reprint requests: Jeffrey B. Smith, M.D., Ph.D., Pediatrics/ Neonatology B2-325 UCLA Center for the Health Sciences, 10833 Le Conte Ave. Los Angeles, CA 90024.

Supported in part by funds provided by the Committee on Research of the Academic Senate of the Los Angeles Division of the University of California and by Cancer Center Core Grant CA-16042.

'Presented in part at the Annual Meeting of the Society for Leukocyte Biology, Charleston, SC, December 1992. migration through the endothelium (5-8). L-selectin was previously known as the lymph node homing receptor LEC.CAM-1, LECAM-1, LAM-1, or as the molecule identified by the MEL14, Leu-8, TQ1, and DREG.56 MAb (9-12).

Abnormalities in the expression and function of L-selectin and other leukocyte adhesion molecules may contribute to the increased susceptibility of newborn infants to life-threatening bacterial and fungal infections (13-16). Neutrophils from cord blood of term infants or from 12- to 48-h-old neonates express significantly less L-selectin than neutrophils from adults $(16,17)$, and reduced $\mathrm{L}$-selectin expression is correlated with diminished adhesion of cord blood neutrophils to IL-1-stimulated endothelium under conditions of flow (16). Expression of L-selectin on neonatal eosinophils is reduced compared with adult eosinophils to a similar extent as on neonatal neutrophils (17). Eosinophils from both neonates and adults express L-selectin at about one third the level of neutrophils in the same specimens (17).

The mechanism responsible for the reduced expression of $\mathrm{L}$ selectin on neonatal neutrophils and eosinophils is not known. One important possibility is that this is a developmentally determined feature of the phenotype of granulocytes in fetal life that persists into the newborn period. If so, we would expect a reduction in L-selectin expression on granulocytes of the preterm fetus similar to or more pronounced than the reduction on granulocytes from term neonates. The purpose of this study was to determine whether the expression of L-selectin on neutrophils and eosinophils from fetal blood is reduced compared with adult controls.

The characterization of circulating granulocytes in the fetus poses significant technical difficulties because of the limited availability and small volume of blood specimens (usually less than $1 \mathrm{~mL}$ ). In addition, neutrophil counts in the 2 nd-trimester fetus are very low, averaging 240 to 350 per $\mathrm{mm}^{3}$ at 22 to $29 \mathrm{wk}$ (18). Because the small number of cells available makes purification procedures impractical, we have used flow cytometry to study mixed leukocyte specimens from whole blood. In normal adult blood, granulocytes (neutrophils and eosinophils) can easily be distinguished from other blood cells by their light-scattering properties (19). Because most granulocytes in adult blood are neutrophils, the presence of eosinophils often may be ignored. However, this cannot be assumed to be valid in fetal blood. We previously showed that eosinophils constituted a surprisingly large proportion of granulocytes in fetuses with $\mathrm{Rh}$ disease, averaging $61 \%$ of granulocytes in seven specimens at 20 to 26 wk gestation and $37 \%$ in 11 specimens at 28 to $34 \mathrm{wk}$ gestation (20). In this study, therefore, we measured the expression of Lselectin on neutrophils and eosinophils using a dual-labeling method we developed that allows these cells to be distinguished $(17,21)$.

\section{MATERIALS AND METHODS}

Subjects. Fetal blood was obtained by percutaneous umbilical cord blood sampling under ultrasound guidance for diagnosis or 
treatment of fetuses with material isoimmunization for $\mathrm{Rh}$ (two fetuses), Kell (one fetus), and PLl antigens (two fetuses), and from one fetus with multiple anomalies. This study used small amounts of fetal blood $(0.5-1.0 \mathrm{~mL})$ that sometimes remained after required tests had been performed and that would otherwise have been discarded. The study involved no alteration in the clinical care of mother or fetus. In fetuses receiving an intrauterine transfusion, samples were obtained before the transfusion was given. Control specimens were drawn from healthy adult volunteers by venipuncture. The specimens were obtained, with appropriate consent, in accordance with an approved institutional protocol.

Materials. PE-conjugated anti-Leu-8 ( $\operatorname{lgG}_{2 \mathrm{a}}$ isotype, anti-Lselectin), PE-conjugated control $\mathrm{MAb}\left(\operatorname{IgG}_{2 \mathrm{a}}\right.$ isotype, clone $\left.\mathrm{X} 39\right)$, and FITC-conjugated anti-Leu-11a (IgG, isotype, CD16) were obtained from Becton Dickinson (Mountain View, CA). PEconjugated beads from Flow Cytometry Standards Corporation (Research Triangle Park, NC) were used in each experiment as a fluorescence standard. Calcium ionophore A23187 and FMLP were obtained from Sigma Chemical (St. Louis, MO). HBSS without bicarbonate or phenol red was obtained from GIBCO BRL (Grand Island, NY), supplemented with $2 \%$ by volume heat-inactivated fetal bovine serum (HBSS-FCS), adjusted to $\mathrm{pH}$ 7.35-7.40, and maintained sterile until use.

Cell preparation. Leukocyte suspensions were prepared, stimulated with activating factors, and labeled with MAb as described (17). Briefly, EDTA-anticoagulated blood specimens were placed on ice immediately after collection, and erythrocytes were removed by two cycles of hypotonic lysis. Except as specified, the cells were kept at $0-4^{\circ} \mathrm{C}$ in HBSS-FCS without calcium and magnesium. Wright-stained smears of whole blood and of cytocentrifuge preparations of the leukocyte suspensions were made for each specimen. When sufficient amounts of blood were available, aliquots of leukocytes were incubated for $20 \mathrm{~min}$ at $37^{\circ} \mathrm{C}$ with FMLP, A23187, or buffer alone (HBSS-FCS with calcium and magnesium), in parallel with aliquots kept cold. After resuspension in cold buffer containing $0.1 \%$ sodium azide, the cells were incubated for $30 \mathrm{~min}$ on ice with saturating amounts of PE-conjugated anti-Leu-8 (or control MAb) together with FITC-conjugated anti-Leu-11a, then washed to remove unbound antibody, and resuspended in $0.3 \mathrm{~mL}$ of azide buffer for analysis.

Flow cytometry. Analysis of granulocyte populations and measurement of L-selectin expression were performed on a FACScan flow cytometer (Becton Dickinson) as described $(17,21)$. Specific granulocyte populations were identified by a combination of light scatter and CD16 fluorescence gating as follows. First, light-scatter gates were used to select the high side-scatter region (the "granulocyte" region) containing neutrophils and eosinophils and excluding lymphocytes, monocytes, and basophils (19). The CD16-bright cells were identified as neutrophils. The CD16-dim cells fell into distinct subpopulations with lowand high-forward light scatter. The CD16-dim cells with lowforward light scatter were identified as eosinophils $(17,19,21)$. The CD16-dim cells with high-forward light scatter were not specifically identified in this study. This cell population, previously observed in umbilical cord blood from term newborns (17, 21 ), was present in significant numbers in some fetal blood specimens but was not found in adult blood. L-selectin expression of the neutrophils or eosinophils was calculated as the mean red fluorescence of cells labeled with PE-Leu- 8 minus that of the same cells labeled with PE-conjugated control MAb. All fluorescence data were collected using linear amplification, with corrections for spectral overlap (color compensation).

Statistics. Mean fluorescence values of the individual Leu- 8 (and control) distributions were calculated with the LYSIS II program (Becton Dickinson). Group statistics were calculated with StatView SE (Brainpower Inc., Calabasas, CA) on a Macintosh computer (Apple Computer, Cupertino, CA) and results were expressed as the group means $\pm \mathrm{SD}$ of the individual distribution mean values. Statistical differences were assessed by repeated-measures analysis of variance and the paired $t$ test.

\section{RESULTS}

Fetal gramulocites. Eight blood specimens were obtained from fetuses at 23 to 34 wk of gestation. Two fetuses were studied twice. The blood cell counts and clinical indications for fetal blood sampling are shown in Table 1. Absolute neutrophil and eosinophil counts were calculated from the total white blood cell count (corrected for nucleated erythrocytes) and 200-cell leukocyte differential counts of whole blood smears. Eosinophils ranged from $130-690$ cells $/ \mathrm{mm}^{3}$ (mean $\pm \mathrm{SD}, 350 \pm 220$ ), and neutrophils ranged from 90 to 3130 cells $/ \mathrm{mm}^{3}$. The ratio of eosinophils to the sum of eosinophils and neutrophils in these specimens ranged from 10 to $88 \%$ (mean \pm SD, $42 \pm 26 \%$ ).

In agreement with the counts obtained from blood smears, the fetal granulocytes identified by flow cytometry contained a much larger proportion of eosinophils than did those from adults (Table 2 ). In the fetal specimens, only $52 \pm 19 \%$ (mean \pm SD) of the cells included in the granulocyte light-scatter gates were neutrophils, as identified by their bright expression of CD16. Most of the other cells were eosinophils, identified as CD16-dim cells with low-forward light scatter. A population of CD16-dim cells with high-forward light scatter constituted the remainder. In contrast to the fetal specimens, $95 \%$ of granulocytes in the adult specimens were neutrophils and all the rest were eosinophils.

Our flow cytometric method for identifying neutrophils and eosinophils was previously validated for neonatal and adult blood specimens by cell sorting experiments (17). Cell sorting could not be performed for the fetal specimens in this study because the number of cells available was insufficient. To validate the identification of neutrophils and eosinophils in these specimens, we compared the flow cytometry results for their relative proportions with the results obtained by enumeration of 200 neutrophils and cosinophils on a Wright-stained slide prepared by cytocentrifugation from the same cell suspensions. Specifically, we evaluated the ratio of eosinophils to the sum of eosinophils and neutrophils, $E /(E+N)$. The values for this ratio obtained by flow cytometry and by enumeration were highly correlated $\left(r^{2}=0.97, p=0.0001\right)$, and the slope of the regression line was 0.95 (Fig. 1). This verifies that eosinophils and neutrophils were accurately identified and that the unidentified cells in the CD16dim, high-forward scatter subpopulation did not include significant numbers of either neutrophils or eosinophils.

L-Selectin expression. L-Selectin expression was measured on unstimulated neutrophils and eosinophils from six pairs of fetal and adult blood specimens (Fig. 2). L-Selectin expression on fetal and adult neutrophils did not differ (mean \pm SD specific fluorescence, $53.0 \pm 6.8$ versus $56.6 \pm 4.3, p=0.3$ ), in striking contrast to the $35-50 \%$ reduction previously reported for neonatal neutrophils $(16,17)$. Similarly, L-selectin expression on fetal and adult eosinophils did not differ (specific fluorescence 16.0 16.5 versus $18.7 \pm 3.2, p=0.4$ ). Fetal eosinophils expressed about one third the level of L-selectin as neutrophils in the same specimens, $p<0.0001$, as previously reported for adults (17). There was no correlation of $\mathrm{L}$-selectin expression with gestational age of the fetus for either neutrophils or eosinophils.

Shedding of L-selectin. Stimulation of neutrophils with the chemotactic peptide FMLP or with other activating factors produces a virtually complete loss of L-selectin expression in a few minutes, caused by the proteolytic cleavage of the molecule with shedding of a soluble fragment that is about $5 \mathrm{kD}$ smaller than the cell-associated form (22-24). Eosinophils shed L-selectin when stimulated with calcium ionophore A23187 (17). To determine whether fetal neutrophils and eosinophils shed L-selectin normally, we evaluated the expression of L-selectin on fetal neutrophils and eosinophils after stimulation in vitro (Fig. 3). Fetal as well as adult neutrophils incubated with FMLP or A23187 lost more than $98 \%$ of their initial level of L-selectin 
Table 1. Fetal subjects and cell counts*

\begin{tabular}{|c|c|c|c|c|c|c|c|}
\hline $\begin{array}{c}\text { Wk of } \\
\text { gestation }\end{array}$ & $\begin{array}{l}\text { Indication } \\
\text { for PUBS }\end{array}$ & $\begin{array}{l}\text { Previous } \\
\text { transfusion }\end{array}$ & $\begin{array}{c}\text { Hematocrit } \\
\left(\sigma_{\%}^{*}\right)\end{array}$ & Platelets & $\begin{array}{l}\text { Total } \\
\text { WBC }\end{array}$ & Neutrophils & Eosinophils \\
\hline 23 & $\mathrm{Rh}$ & No & 15.3 & & 5200 & 1700 & 180 \\
\hline 24 & Anomalies & No & & & 3100 & 220 & 230 \\
\hline 25 & Kell & No & 5.3 & & 1900 & 170 & 130 \\
\hline 25 & PLl & No & 37.0 & 38000 & 3800 & 260 & 300 \\
\hline 28 & PLl & Platelets & 35.2 & 81000 & 2500 & 230 & 220 \\
\hline 29 & $\mathrm{Rh}$ & $\mathrm{RBC}$ & 29.3 & & 6700 & 2400 & 400 \\
\hline 29 & Kell & $\mathrm{RBC}$ & 21.0 & & 2200 & 90 & 660 \\
\hline 34 & PL1 & Platelets & 31.5 & 9000 & 9800 & 3130 & 690 \\
\hline
\end{tabular}

*Cells/mm ${ }^{3}$. PUBS, percutaneous umbilical cord blood sampling; WBC, white blood cells; RBC, red blood cells.

Table 2. Subpopulations of granulocite's in fetal and adult blood*

\begin{tabular}{|c|c|c|c|c|c|}
\hline \multirow[b]{2}{*}{ Subpopulation } & \multirow[b]{2}{*}{ Cell type } & \multicolumn{2}{|c|}{ Fetal granulocytes } & \multicolumn{2}{|c|}{ Adult granulocytes } \\
\hline & & Mean $\pm S D$ & Range & Mean \pm SD & Range \\
\hline CD16 bright & Neutrophils & $52 \pm 19 \%$ & $30-78 \%$ & $95 \pm 3 \%$ & $90-98 \%$ \\
\hline CDI6 dim, with low FSC & Eosinophils & $34 \pm 20 \%$ & $5-57 \%$ & $4 \pm 3 \%$ & $2-9 \%$ \\
\hline CDI6 dim, with high FSC & Unidentified & $12 \pm 6 \%$ & $5-22 \%$ & $0.1 \pm 0.1 \%$ & $0-0.2 \%$ \\
\hline
\end{tabular}

* Fetal and adult leukocytes from whole blood were labeled with FITC-conjugated anti-Leu-1 la MAb (CD16) and characterized by flow cytometry using CD16 expression and forward light scatter (FSC) as described in Materials and Methods. The values are the proportion of each subpopulation of granulocytes for eight fetal and six adult specimens.

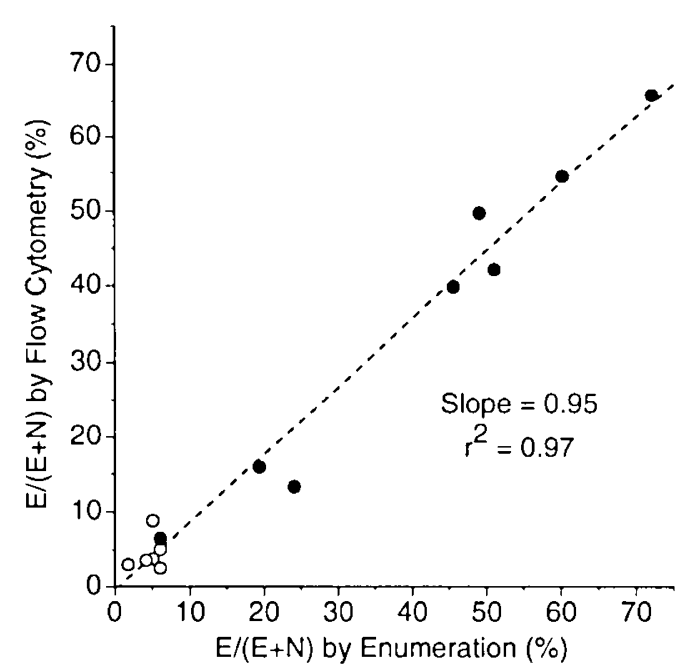

Fig. 1. Validation of the identification of eosinophils and neutrophils by flow cytometry. The ratio of eosinophils to the sum of cosinophils and neutrophils, $E /(E+N)$, was obtained by flow cytometry as described and compared with the value obtained by enumeration of cells on Wrightstained cytocentrifuge preparations from the same specimen for eight fetal $(\bullet)$ and six adult blood samples $(O)$.

expression $(p<0.001)$. Incubation at $37^{\circ} \mathrm{C}$ in buffer alone did not produce a significant reduction in neutrophil L-selectin expression compared with neutrophils kept cold. Fetal eosinophils incubated with A23187 lost more than $98 \%$ of their initial level of $\mathrm{L}$-selectin expression, as did adult eosinophils, $(p<0.01)$. FMLP produced significant shedding of $\mathrm{L}$-selectin from fetal eosinophils, $(p<0.01)$, but not from adult eosinophils. The expression of L-selectin on control eosinophils incubated in buffer alone did not differ from that of unstimulated eosinophils.

\section{DISCUSSION}

In this study, we have shown that unstimulated fetal neutrophils and eosinophils express L-selectin at levels that are not reduced compared with those of adult cells. Thus, by 23 to 25 wk of gestation, the fetus is capable of producing neutrophils and eosinophils with mature levels of $\mathrm{L}$-selectin expression. This is in striking contrast to the significant reductions in L-selectin expres-

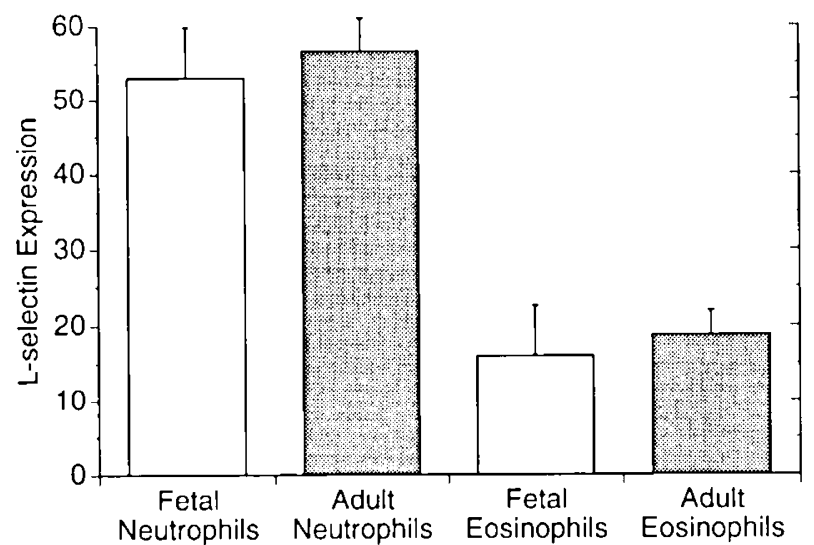

Fig. 2. Expression of L-selectin on unstimulated fetal and adult neutrophils and eosinophils. Leukocytes kept unstimulated at $0-4^{\circ} \mathrm{C}$ were labeled with $\mathrm{MAb}$ and analyzed as described. The figure shows the specific L-selectin fluorescence (mean \pm SD) on neutrophils and eosinophils from six pairs of fetal and adult specimens.

sion previously reported for neutrophils and eosinophils from term neonates $(16,17)$. The expression of normal levels of $\mathrm{L}$ selectin on the fetal cells implies that the abnormalities of Lselectin expression on neonatal neutrophils are not the result of an intrinsic developmental limitation but rather are caused by changes occurring in the neonatal period. The specific nature of these changes is not known and is an important subject for future studies.

Although the fetuses in this study do not represent a normal population, the finding of normal levels of L-selectin expression on their neutrophils and eosinophils is unlikely to be the result of fetal illness or abnormality. Shedding of L-selectin, rather than an increase, would be the expected effect of fetal illness because there are no known mechanisms that produce increased expression of L-selectin on neutrophils and eosinophils (23-25). Furthermore, the variation of $\mathrm{L}$-selectin expression among the fetal specimens was similar to that of the adult controls, despite the diversity of clinical problems in these fetuses. By showing that the fetal neutrophils and eosinophils shed L-selectin normally when stimulated with FMLP or A23187, we also ruled out the possibility that their normal levels of L-selectin could be due to an impairment of shedding. 

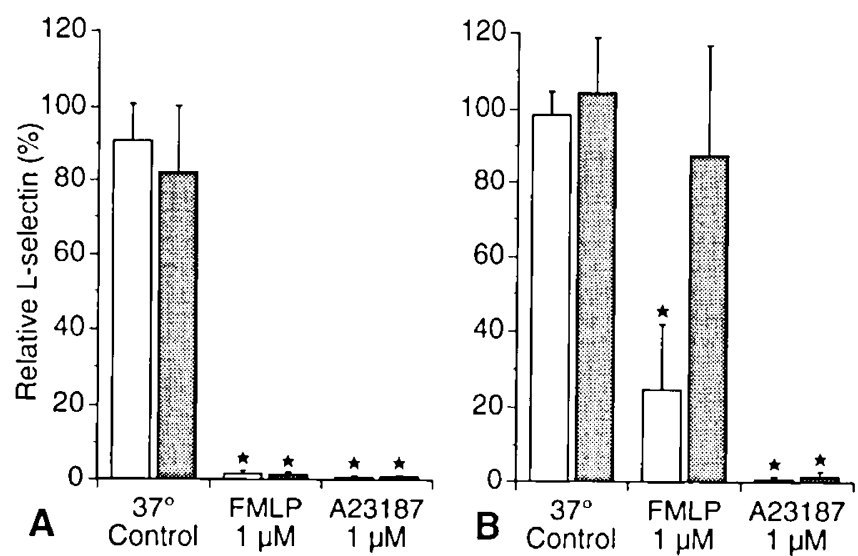

Fig. 3. Shedding of L-selectin from neutrophils $(A)$ and cosinophils $(B)$ in response to incubation with activating factors. Leukocytes from six pairs of fetal (white bars) and adult blood specimens (shaded bars) were kept unstimulated at $0-4^{\circ} \mathrm{C}$ or incubated for $20 \mathrm{~min}$ at $37^{\circ} \mathrm{C}$ in buffer alone $\left(37^{\circ} \mathrm{C}\right.$ control), or in buffer containing FMLP or A23187. The leukocytes were labeled with MAb and analyzed as described in Materials and Methods. For each cell type and treatment, the L-selectin remaining after incubation is shown as a percentage (mean $\pm \mathrm{SD}$ ) of its expression on the unstimulated cells kept at $0-4^{\circ} \mathrm{C} . \star, p<0.01$ is the $37^{\circ}$ control for each cell type.

An important feature of this study was the use of CD16 expression combined with light scatter characteristics to identify neutrophils and eosinophils in the fetal blood specimens. This provided a more general method for discriminating fetal neutrophils and eosinophils by flow cytometry than in our previous study, in which neutrophils were distinguished from eosinophils by their distinctly higher levels of expression of CD11b/CD 18 or CD35 after stimulation with FMLP. Dual-labeling with CD16 makes it possible to distinguish eosinophils and neutrophils both before and after stimulation and permits the study of cell-surface molecules whose expression on neutrophils and eosinophils produces overlapping fluorescence distributions. As emphasized previously $(17,21)$, the method requires careful handling of blood specimens and prompt analysis to minimize the potential loss of CD16 from neutrophils.

This study extends our previous finding of a large proportion of eosinophils in fetuses with $\mathrm{Rh}$ disease by demonstrating that a large eosinophil ratio also may occur in fetuses in Kell- and PLl-isoimmunized pregnancies. Because neutrophils constituted, on average, only $52 \%$ of granulocytes in the fetal specimens in this study, failure to distinguish neutrophils from eosinophils (and other CD16-negative cells in the granulocyte scatter region) would have produced a falsely decreased estimate of fetal neutrophil L-selectin expression, inasmuch as eosinophils expressed only $30 \%$ as much L-selectin as neutrophils. Failure to distinguish among the fetal granulocyte types probably accounts for the apparent finding by Koenig et al. (26) that fetal "neutrophils" were less sensitive to stimulation with FMLP than those of adults in contrast to our results that showed normal shedding of $\mathrm{L}$ selectin by FMLP-stimulated fetal neutrophils.

Our data suggest that fetuses in isoimmunized pregnancies may have a relative eosinophilia compared with normal fetuses. Our patient population did not include normal fetuses, but others have reported blood cell counts for fetuses evaluated for toxoplasmosis who subsequently proved to be uninfected $(18,27)$. From the data reported by Forestier et al. (18) for 374 normal fetuses from 22 to $29 \mathrm{wk}$, we calculate that eosinophils averaged $110-160$ per $\mathrm{mm}^{3}$ with an estimated SD of about 120 per $\mathrm{mm}^{3}$. In contrast, the eosinophil count for the six specimens from isoimmunized pregnancies at $23-29 \mathrm{wk}$ in this study was twice as large, $315 \pm 190$ (mean $\pm \mathrm{SD}$ ). In addition, the eosinophils in these fetuses may be partially activated or "primed" because unlike eosinophils from normal adults, they shed significant amounts of L-selectin when exposed to $\operatorname{FMLP}(17,21)$. Currently, the possible role of eosinophils in the pathophysiology of fetal isoimmune disease is unknown. Further investigation of these observations will be a goal of future studies.

The lack of a developmental limitation of L-selectin expression does not guarantee the absence of a developmental component for other abnormalities of neonatal neutrophils. Regulation of the surface expression and avidity of CD11b/CD18, one of the $\beta_{2}$-integrins, is of particular interest. Several groups of investigators have shown that neonatal neutrophils have an impaired ability to upregulate $\mathrm{CD} 1 \mathrm{lb} / \mathrm{CD} 18$ expression in response to stimulation $(14,20,28)$, and we have shown that neonatal eosinophils have a similar impairment (21). Furthermore, neonatal neutrophils have significant abnormalities of CD $1 \mathrm{lb} /$ CD18-dependent transendothelial migration (15). Although a direct link between these phenomena has not yet been demonstrated, Hughes et al. (29) have recently shown that up-regulation of CD $11 \mathrm{~b} / \mathrm{CD} 18$ expression is functionally important in adherence-dependent locomotion. In a previous study, we found that neutrophils from fetuses with $\mathrm{Rh}$ disease had impaired upregulation of both $C D 11 \mathrm{~b} / \mathrm{CD} 18$ and CD35 (20). It is not known whether a developmental limitation, an effect of illness, or both factors are responsible for the impaired up-regulation of these receptors on fetal neutrophils. In contrast, $\mathrm{CD} 16\left(\mathrm{Fc} \gamma \mathrm{R}_{\mathrm{III}}\right)$, like L-selectin in this study, was expressed at normal adult levels on the unstimulated neutrophils of fetuses with $\mathrm{Rh}$ disease (20). Thus, two receptors, L-selectin and CD16, have been found to be expressed at normal adult levels on unstimulated fetal neutrophils, whereas fetal neutrophils stimulated with FMLP had impaired up-regulation of CD11b/CD18 and CD35. This suggests the interesting possibility that fetal neutrophils could have a developmental limitation of these activation-dependent processes. Studies of neutrophils from normal fetuses will be needed to validate this speculation.

Because neutrophils and eosinophils in the preterm fetus can express L-selectin at levels equal to those of adults, we conclude that the reduction of $\mathrm{L}$-selectin expression on neutrophils and eosinophils of neonates is not the result of an inherent developmental limitation. This supports the alternative concept that Lselectin-related defects in neonatal neutrophil adherence are caused by physiologic changes occurring in the neonatal period. Such changes also may be responsible for some other important abnormalities of neonatal neutrophil adherence. Elucidation of the specific etiology of these changes may make it possible to devise preventive or therapeutic strategies to normalize the adherence-related functions of neonatal neutrophils and lower the risk of neonatal sepsis.

Acknowledgment. The authors thank the Johnson Comprehensive Cancer Center, UCLA, for the use of the Flow Cytometry Core Laboratory.

\section{REFERENCES}

1. Lewinsohn DM, Bargatze R.F, Butcher EC 1987 Leukocyte-endothelial cell recognition: evidence of a common molecular mechanism shared by neutrophils, lymphocytes, and other leukocytes. J Immunol 138:4313-4321

2. Butcher EC 1991 Leukocyte-endothelial cell recognition: three (or more) steps to specificity and diversity. Cell 67:1033-1036

3. Lawrence MB, Springer TA 1991 Leukocytes roll on a selectin at physiologic flow rates: distinction from and prerequisite for adhesion through integrins. Cell 65:859-873

4. Ley K, Gaehtgens P, Fennie C, Singer MS, Lasky LA, Rosen SD 1991 Lectinlike cell adhesion molecule 1 mediates leukocyte rolling in mesenteric venules in vivo. Blood 77:2553-2555

5. von Andrian UH, Chambers JD, McEvoy LM, Bargatze RF, Arfors KE Butcher EC 1991 Two-step model of leukocyte-endothelial cell interaction in inflammation: distinct roles for LECAM- 1 and the leukocyte $\beta_{2}$ integrins in vivo. Proc Natl Acad Sci USA 88:7538-7542

6. von Andrian UH, Hansell P, Chambers JD, Berger EM, Filho IT, Butcher EC Arfors KE 1992 L-selectin function is required for $\beta_{2}$-integrin-mediated neutrophil adhesion at physiological shear rates. Am J Physiol 263:H1034H1044

7. Lasky LA 1992 Selectins: interpreters of cell-specific carbohydrate information during inflammation. Science 258:964-969 
8. Smith CW 1992 Transendothelial migration. In: Harlan JM, Liu DY (eds) Adhesion: Its Role in Inflammatory Disease. WH Freeman, San Francisco, pp 83-115

9. Bevilacqua M, Butcher E, Furie Barbara, Furie Bruce, Gallatin M, Gimbrone M. Harlan J, Kishimoto K, Lasky L, McEver R, Paulson J. Rosen S, Seed B, Siegelman M, Springer T, Stoolman L, Tedder T, Varki A, Wagner D. Weissman I, Zimmerman G 1991 Selectins: a family of adhesion receptors. Cell $67: 233$

10. Camerini D, James SP, Stamenkovic I, Seed B 1989 Leu-8/TQ1 is the human equivalent of the Mel-14 lymph node homing receptor. Nature 342:78-82

11. Tedder TF, Penta AC, Levine HB, Freedman AS 1990 Expression of the human leukocyte adhesion molecule, LAM1: identity with the TQ1 and Leu-8 differentiation antigens. J Immunol 144:532-540

12. Kishimoto TK, Jutila MA, Butcher EC 1990 Identification of a human peripheral lymph node homing receptor: a rapidly down-regulated adhesion molecule. Proc Natl Acad Sci USA 87:2244-2248

13. Hill HR 1987 Biochemical, structural, and functional abnormalities of polymorphonuclear leukocytes in the neonate. Pediatr Res 22:375-382

14. Anderson DC, Freeman KLB, Heerdt B, Hughes BJ, Jack RM, Smith CW 1987 Abnormal stimulated adherence of neonatal granulocytes: impaired induction of surface MAC-1 by chemotactic factors or secretagogues. Blood 70:740-750

15. Anderson DC, Rothlein R, Marlin SD, Krater SS, Smith CW 1990 Impaired transendothelial migration by neonatal neutrophils: abnormalities of Mac- 1 (CD11b/CD18)-dependent adherence reactions. Blood 76:2613-2621

16. Anderson DC, Abbassi O, Kishimoto TK. Koenig JM, McIntire LV, Smith CW 1991 Diminished lectin-, epidermal growth factor-, complement binding domain-cell adhesion molecule-1 on neonatal neutrophils underlies their impaired CD18-independent adhesion to endothelial cells in vitro. J Immunol 146:3372-3379

17. Smith JB, Kunjummen RD, Kishimoto TK. Anderson DC 1992 Expression and regulation of $\mathrm{L}$-selectin on eosinophils from human adults and neonates. Pediatr Res 32:465-471

18. Forestier F, Daffos F, Catherine N, Renard M, Andreux JP 1991 Developmental hematopoiesis in normal human feta! blood. Blood 77:2360-2363
19. Terstappen LW, Hollander Z, Meiners H, Loken MR 1990 Quantitative comparison of myeloid antigens on five lineages of mature peripheral blood cells. J Leukoc Biol 48:138-148

20. Smith JB, Campbell DE, Ludomirsky A, Polin RA, Douglas SD, Garty BZ Harris MC 1990 Expression of the complement receptors CR 1 and CR 3 and the type III Fc, receptor on neutrophils from newborn infants and from fetuses with Rh disease. Pediatr Res 28:120-126

21. Smith JB, Kunjummen RD, Raghavender BH 1991 Eosinophils and neutrophils of human neonates have similar impairments of quantitative upregulation of Mac-1 (CD11b/CD 18) expression in vitro. Pediatr Res 30:355-361

22. Berg M. James SP 1990 Human neutrophils release the Leu-8 lymph node homing receptor during cell activation. Blood 76:2381-2388

23. Kishimoto TK. Jutila MA. Berg EL, Butcher EC 1989 Neutrophil Mac-1 and MEL-14 adhesion proteins inversely regulated by chemotactic factors. Science 245:1238-1241

24. Schlieffenbaum B. Spertini O. Tedder TF 1992 Soluble L-selectin is present in human plasma at high levels and retains functional activity. J Cell Biol 119:229-238

25. Griffin JD, Spertini O, Ernst TJ, Belvin MP, Levine HB, Kanakura Y, Tedder TF 1990 Granulocyte-macrophage colony-stimulating factor and other cytokines regulate surface expression of the leukocyte adhesion molecule- 1 on human neutrophils, monocytes, and their precursors. J Immunol 145:576584

26. Koenig JM, Anderson DC, Smith CW 1992 Surface levels of L-selectin on fetal neutrophils are less sensitive to stimulation than are those of adult neutrophils. Pediatr Res 31:268A(abstr)

27. Davies NP, Buggins AGS, Snijders RJM, Jenkins E, Layton DM, Nicolaides KH 1992 Blood leucocyte count in the human fetus. Arch Dis Child 67:399403

28. Bruce MC, Baley JE, Medvik KA, Berger M 1987 Impaired surface membrane expression of $\mathrm{C} 3 \mathrm{bi}$ but not $\mathrm{C} 3 \mathrm{~b}$ receptors on neonatal neutrophils. Pediatr Res 21:306-311

29. Hughes BJ, Hollers JC. Crockett-Torabi E, Smith CW 1992 Recruitment of CD1 Ib/CD18 to the neutrophil surface and adherence-dependent cell locomotion. J Clin Invest 90:1687-1696 